Journal of Case Reports 2018;8(2):105-108

\title{
Regression of Renal Failure after Unilateral Simple Nephrectomy
}

\author{
Ümit Eskidemir ${ }^{1}$, Burak Turna ${ }^{2}$ \\ Department of Urology, ${ }^{1}$ Şanlıurfa Siverek Public Hospital and ${ }^{2}$ Ege University School of Medicine, Turkey.
}

\author{
Corresponding Author: \\ Dr. Ümit Eskidemir \\ Email: dr.eskidemir@gmail.com \\ This is an Open Access article distributed \\ under the terms of the Creative Commons \\ Attribution License (creativecommons.org/ \\ licenses/by/3.0). \\ Received : December 3, 2017 \\ Accepted : March 30, 2018 \\ Published : April 25, 2018
}

\begin{abstract}
Background: Chronic kidney disease is widely recognized as a significant public health concern. Kidney stones are infrequently implicated as the primary cause of end-stage renal disease. Case Report: We report a case of chronic kidney disease and concomitant unilateral kidney stone with ipsilateral non-functioning kidney which surprisingly regresses after unilateral simple nephrectomy. Conclusion: Removal of the non-functioning hydronephrotic kidney with kidney stone should be kept in mind in the presence of renal failure.
\end{abstract}

Keywords: Chronic Kidney Failure, Kidney Calculi, Nephrectomy, Renal Insufficiency, Urolithiasis.

\section{Introduction}

Chronic kidney disease (CKD) is widely recognized as a significant public health concern [1]. Epidemiological evidence suggests that patients with urolithiasis are at increased risk for end-stage renal disease (ESRD) [2]. However, kidney stones are infrequently implicated as the primary cause of ESRD (0.2-3.2\% of all ESRD cases) [3-5]. It is unclear if urological intervention impacts the progression of CKD with regards to urolithiasis [2]. Herein, we report a case of CKD and concomitant unilateral kidney stone with ipsilateral nonfunctioning kidney which surprisingly regressed after unilateral simple nephrectomy.

\section{Case Report}

A sixty-eight year old male presented to the emergency departmant of our hospital with nausea and fatigue. He had a history of long-standing right nephrolithiasis, however the patient did not want any intervention for this stone in the past. He was on treatment with amlodipine $(10 \mathrm{mg} /$ day $)$ for hypertension for 10 years. He had no other known disease or history of nephrotoxic drug use. Physical examination was unremarkable with a blood pressure level of 120/60 $\mathrm{mmHg}$. Routine laboratory tests revealed the following values: serum creatinine $5.1 \mathrm{mg} / \mathrm{dL}(0.7-1.3 \mathrm{mg} / \mathrm{dL})$, blood urea nitrogen $(B U N) 80 \mathrm{mg} / \mathrm{dL}(10-50 \mathrm{mg} / \mathrm{dL})$, $\mathrm{K}^{+} 4.1 \mathrm{mmol} / \mathrm{L}(3.5-5 \mathrm{mmol} / \mathrm{L})$, hematocrit $33.2 \%$ (41.5-50.4\%), hemoglobin $10.5 \mathrm{~g} / \mathrm{dL}$ (13.5-17.5 g/ dL). Calculated creatinine clearance by CockcroftGault formula was $26.7 \mathrm{ccs} / \mathrm{min}$ (61-114 ccs/ $\mathrm{min})$. There were no signs of hyperuricemia or hypercalcemia in biochemical analysis. Urine culture was sterile and no other infectious sites were detected. All other tests were within normal ranges.

The patient underwent emergent hemodialysis and he was then hospitalized by the nephrology department for the evaluation of the etiology of renal failure. Spot urine test was normal and 24 hour urine analysis demonstrated a total of $1440 \mathrm{ml}$ urine/24 hours with urine creatinine level of $1065 \mathrm{mg} /$ day $(800-2000 \mathrm{mg} /$ day $)$ and BUN $4.1 \mathrm{~g} /$ day. Despite conservative management and fluid restriction, his creatinine levels worsened and he developed metabolic acidosis ( $\mathrm{pH}$ : 7.24, BE: $\mathrm{HCO}^{-} 19$ in pre-dialysis blood gas analysis). The patient required hemodialysis three times a week. 
Further laboratory evaluation revealed thyroid stimulating hormone: $1.17 \mu \mathrm{IU} / \mathrm{mL}(0.35-5.5 \mu \mathrm{IU} /$ $\mathrm{mL}$ ), free triiodothyronine $2.03 \mathrm{pg} / \mathrm{mL}(2.3-4.2$ $\mathrm{pg} / \mathrm{mL})$, free thyroxine $1.21 \mathrm{ng} / \mathrm{dL}(0.79-1.76 \mathrm{ng} /$ $\mathrm{dL})$, parathormone $162 \mathrm{pg} / \mathrm{mL}(12-88 \mathrm{pg} / \mathrm{mL})$, phosphorus $7.3 \mathrm{mg} / \mathrm{dL}(2.3-4.5 \mathrm{mg} / \mathrm{dL})$, ferritin $271.5 \mathrm{ng} / \mathrm{mL}$ (30-400 ng/mL), B12 $183 \mathrm{pg} / \mathrm{mL}$ (197-866 pg/mL), folic acid $11.52 \mathrm{ng} / \mathrm{mL}$ (4.6-18.7 $\mathrm{ng} / \mathrm{mL})$. He was never oliguric; his daily urine output remained stable with a volume of 1000$2500 \mathrm{ml}$. With these results his renal failure was assumed to be chronic.

The ultrasonography revealed an enlarged right kidney with atrophic parenchyma, multiple stones (a large pelvic stone and multiple calyceal stones in the lower calyx) and grade 4 hydronephrosis. Left kidney appeared normal which was confirmed with non-contrast tomography [Fig.1]. A $27 \mathrm{~mm}$ right pelvic stone seemed to obstruct the kidney resulting in renal atrophy. Despite not being able to explain the etiology of renal failure, the patient underwent right simple nephrectomy for non-functioning kidney. Surprisingly, patient's blood creatinine levels started to decrease after the operation. His preoperative post-dialysis creatinine level was
$2.03 \mathrm{mg} / \mathrm{dL}$ and it gradually decreased to $1.56 \mathrm{mg} / \mathrm{dL}$ on the postoperative day 1 and to $1.29 \mathrm{mg} / \mathrm{dL}$ on the postoperative day 2 . He didn't require hemodialysis after the operation and was discharged home on postoperative day 5 with no need for supportive therapy. Histological examination of right kidney was reported as atrophic kidney with nephrolithiasis and severe hydronephrosis.

\section{Discussion}

Kidney stones are common and the incidence of urolithiasis has been increasing, with lifetime incidences of $10 \%$ for men and $5 \%$ for women in recent studies [6,7]. It is well known that obstructive uropathy causes irreversible damage on the affected kidney if not treated properly. It is claimed that obstructive uropathy affects the contralateral kidney with several mechanisms.

Renal tubulo-intestinal fibrosis (TIF) is a classical hallmark of CKD and is well correlated with the loss of renal function [8]. Development of fibrosis in kidney tissue is a complex process and comprises progressive development of TIF, glomerulosclerosis and loss of glomerular and peritubular capillaries [9]. There are several molecular mechanisms leading to fibrosis in
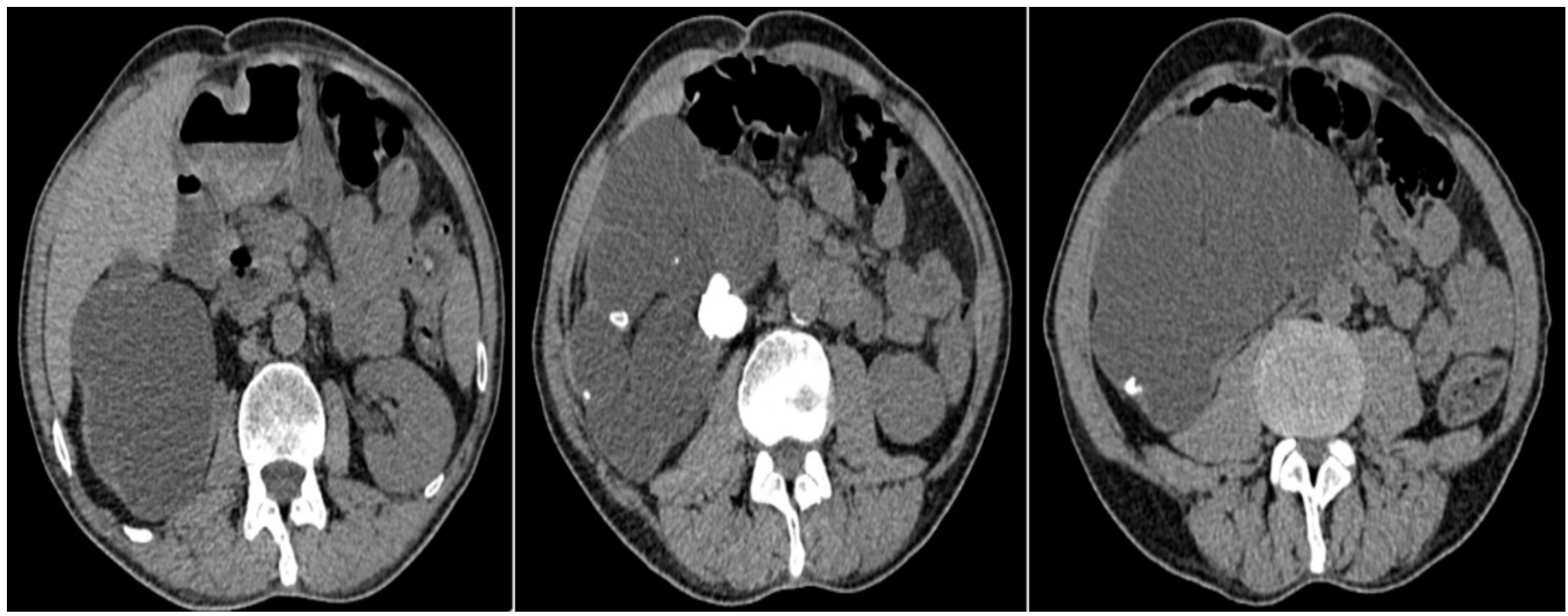

Fig.1: Non-contrast CT images of abdomen which shows normal functioning left kidney and non-functioning hydronephrotic right kidney with a $27 \mathrm{~mm}$ pelvic stone. 
obstructive uropathy. In one study, it is showed that unilateral ureteral obstruction (UUO) induces profibrotic growth factors such as TGF- $\beta 1$ and this profibrotic signaling inhibition attenues kidney fibrosis in the UUO model [10]. TIF involves an excess accumulation of interstitial extracellular matrix and myofibroblasts accompanied by tubule atrophy [11]. Several molecular mechanisms and pathways are identified leading to inflammation on UUO models. Inflammasomes are multiprotein cytoplasmic complexes that serve as pattern recognition receptors, regulates proinflammatory cytokine interleukin-1 $\beta$ (IL-1 $\beta$ ) production [12]. NOD-like receptors family pyrin domaincontaining 3 (NLRP3), the most characterized inflammasome, forms complexes comprised of adaptor proteins such as the apoptosis-associated speck-like protein containing a caspase recruitment domain (ASC) and the serine protease caspase-1 (CASP-1). NLRP3 inflammasome trigers caspase-1 activation and IL-1 $\beta$ maturation in response to diverse stimuli in a murine model of UUO [1315]. IL-1 $\beta$ is synthesized as an inactive precursor molecule by innate immune system and is a proinflamatory cytokine. Infiltrating macrophages are the major source of IL-1 $\beta$ in renal disease. TNF- $\alpha$ and IL- 6 are the other proinflammatory cytokines causing inflammatory process in CKD. Consequently, UUO causes both a local effect on the affected kidney and a systemic effect on other organs by triggered inflammatory process. We think that this inflammatory process may have an effect on contralateral kidney. Kacar et al. showed that UUO led to histopathological alterations on the contralateral kidneys such as cystic dilatation of the renal pelvis, glomerular collapse, epithelial degeneration of the proximal, distal and collector tubules and interstitial edema and inflammation [16]. In our case it is possible that non-obstructed contralateral kidney may be affected due to systemic response to the obstructed hydronephrotic left kidney. Affected contralateral kidney demonstrates decreased function and this results in high serum creatinine levels acting like CKD. This mechanism may explain regression of CKD after removal of hydronephrotic atrophic right kidney in our case.

In hydronephrotic atrophic kidneys high renal pelvic pressure and intrarenal pressure causes renal backflow with moderate leakage to the renal capsule in some cases [17]. This leakage may result in perirenal extravasation and eventually urinary ascites. Sometimes this situation presents as renal pseudo-failure (laboratory abnormalities of acute kidney injury in the setting of normal kidney function) [18-20]. In our case severe obstruction secondary to kidney stone and high intrarenal pressure may be causing perirenal urine extravasation. This clinic manifestation may act like as renal pseudo-failure with high serum creatinine levels. This possibility explains why serum creatinine levels gradually regressed after simple nephrectomy.

\section{Conclusion}

Removal of the non-functioning hydronephrotic kidney with kidney stone should be kept in mind in the presence of renal failure.

Contributors: BT performed the case and did manuscript editing; ÜE assisted to the case and made the follow-up of the patient along with manuscript writing. ÜE will act as guarantor. Both authors approved the final version of this manuscript.

Funding: None; Competing interests: None stated.

\section{References}

1. Shoag J, Halpern J, Goldfarb DS, Eisner BH. Risk of chronic and end stage kidney disease in patients with nephrolithiasis. J Urol. 2014;192:1440-1445.

2. D'Costa M, Savcic-Kos R, Huang J, D.Rule A, Murali N. Urological procedures in urolithiasis and their association with chronic kidney disease. Clin Med Res. 2016;1:75-82.

3. Jungers P, Joly D, Barbey F, Choukroun G, Daudon M. ESRD caused by nephrolithiasis: prevalence, mechanisms, and prevention. Am J Kidney Dis. 2004:44:799-805.

4. Tosetto E, Ghiggeri GM, Emma F, Barbano G, Carrea A, Vezzoli G, et al. Phenotypic and genetic heterogeneity in Dent's disease the results of an Italian collaborative study. Nephrol Dial Transplant. 2006;21:2452-2463. 
5. Collins AJ, Foley RN, Herzog C, Chavers BM, Gilbertson $\mathrm{D}$, Ishani A, et al. Excerpts from the US Renal Data System 2009 Annual Data Report. Am J Kidney Dis. 2010;55(1 Suppl 1):S1-420,A6-7.

6. Rule AD, Krambeck AE, Lieske JC. Chronic kidney disease in kidney stone formers. Clin J Am Soc Nephrol. 2011;6:2069-2075.

7. Worcester EM, Parks JH, Evan AP, Coe FL. Renal function in patients with nephrolithiasis. J Urol. 2006; 176:600-603.

8. Mirzoyan K, Baïotto A, Dupuy A, Marsal D, Denis $\mathrm{C}$, Vinel $\mathrm{C}$, et al. Increased urinary lysophosphatidic acid in mouse with subtotal nephrectomy: potential involvement in chronic kidney disease. J Physiol Biochem. 2016;72:803-812.

9. Louis K, Hertig A. How tubular epithelial cells dictate the rate of renal fibrogenesis? World J Nephrol. 2015;4:367373.

10. Sato M, Muragaki Y, Saika S, Roberts AB, Ooshima A. Targeted disruption of TGF- $\beta 1 / \mathrm{Smad} 3$ signaling protects against renal tubulointerstitial fibrosis induced by unilateral ureteral obstruction. J Clin Invest. 2003;112:1486-1494.

11. Wang L, Ma J, Guo C, Chen C, Yin Z, Zhang X, et al. Danggui Buxue Tang Attenuates Tubulointerstitial fibrosis via suppressing NLRP3 inflammasome in a rat model of unilateral ureteral obstruction. Biomed Res Int. 2016;2016:1-12.

12. Martinon F, Burns K, Tschopp J. The inflammasome: a molecular platform triggering activation of inflammatory caspases and processing of proIL-beta. Mol Cell. 2002; 10:417-426.

13. Medzhitov R. Toll-like receptors and innate immunity. Nat Rev Immunol. 2001;1:135-145.

14. Szabo G, Csak T. Inflammasomes in liver diseases. J Hepatol. 2012;57:642-654.

15. Gross O, Thomas CJ, Guarda G, Tschopp J. The inflammasome: an integrated view. Immunol Rev. 2011;243:136-151.

16. Kaçar M, Çetin E, Çalışkan Y, Balkan E, Kılıç N, Doğruyol $\mathrm{H}$. The early and late period alterations on the contralateral renal parenchyma secondary to unilateral ureteropelvic junction obstruction: experimental study. Turkish Assoc Pediatr Surg. 2010;24:113-120.

17. Eklöf O, Elle B, Thönell S. Pseudotumour of the kidney secondary to posterior urethral valves: the role of renal backflow and perirenal extravasation. Pediatr Radiol. 1984; 14:215-219.

18. Mark A, Meister M, Opara B, Chow R. Nontraumatic urinary bladder rupture presenting as renal pseudofailure and ascites. Radiol Case Reports. 2017;12:304307.

19. Matsumura M, Ando N, Kumabe A, Dhaliwal G. Pseudorenal failure: bladder rupture with urinary ascites. BMJ Case Rep. 2015 Nov 20; 2015: bcr2015212671.

20. Zhou C, Ying X, Feng W. Pseudo-acute renal failure due to intraperitoneal urine leakage. Intern Med. 2015;54:1777-1780. 